EUROPEAN HONORS COUNCIL

Paper

\title{
Different views on assuring the quality of honours programmes
}

\author{
Pierre van Eijl $1^{1 *}$, Henmar Moesker ${ }^{2}$, Marleen Eyckmans ${ }^{3}$
}

1. Utrecht University, The Netherlands, p.j.vaneijl@uu.nl

2. Hanze University of Applied Sciences Groningen, The Netherlands, h.m.moesker@pl.hanze.nl

3. University of Antwerp, Belgium, marleen.eyckmans@uantwerpen.be

*Corresponding author: p.j.vaneijl@uu.nl

Received: 27 January 2017; Accepted: 5 April 2017; Published: XX April 2017

Keywords: quality assurance, honours programmes, certification, annual report, Sirius compass, assessment framework

\begin{abstract}
Can we match formal procedures for quality assurance with the creativity and individuality that defines honours? In a session at the Utrecht Honours Conference 2016: Honours Futures we discussed experiences in quality assurance of honours programmes in the United States of America, the Netherlands and Belgium. To illustrate the possibilities, a case study of using an external audit for honours education and two case studies of the use of internal quality assurance tools in an honours programme were presented. It is concluded that a form of quality assurance is needed to continuously improve. So honours educators must at least care for internal quality control. Student involvement is stimulating for the engagement of all participants in the process of quality control. Internal quality control may result in an annual report. Annual reports can be used both internally and in external quality control.
\end{abstract}

\section{Introduction}

This paper is based on a session at the Utrecht Honours Conference 2016: Honours Futures. During the workshop session, participants were invited to share their own experiences and insights on quality assurance in honours education. One participant shared her experience with an internal certification programme at Utrecht University. Because it enriched the seminar, it was included as the third part of this paper, which thereby consists of five parts:

1. Quality assurance versus freedom in honours?

2. Case study of Hanze University of Applied Sciences - Hobéon Quality Certification; an example of external quality assurance

3. Example of internal certification at the Utrecht University

4. Case study of incorporation of regular quality assurance tools in an honours programme at the University of Antwerp; an example of internal quality control

5. Concluding remarks 


\section{Quality assurance versus freedom in honours?}

High quality honours programmes, cherished by students, teachers and management, are what everyone is looking for. How can we ensure students' freedom and creativity without relying on elaborate checklists by obligatory quality assurance procedures? With the recent increase in honours initiatives all around Europe and especially in the Netherlands, the question of quality assurance of honours programmes begins to rise.

In the last six years the Sirius programme in the Netherlands (governmental support for higher education institutions who wanted to develop honours programmes) was a strong catalyst for the development of honours education. During 2010-2015, an audit committee of Sirius visited the participating universities to discuss the self-study of the honours programmes as 'critical friends' which helped the institutions to gain more insights in their programme's strengths and weaknesses and to implement improvements. It became apparent that external credibility is as important as internal feedback for the programmes to learn and improve. Because honours programmes are often frontrunners in educational change which can also result in innovative changes in regular programmes, they may reflect the quality of tomorrow's education.

\subsection{Finding common ground for a definition of an honours programme}

In the discussion about quality assurance we need to keep in mind that honours programmes require quite some effort and time. Therefore it is important that these programmes are considered to be worthwhile. The programme quality, number of students and added value of the honours programmes are therefore important in this context. The diversity of honours programmes is enormous: disciplinary/multi-/interdisciplinary; academic/professional, different size and duration, regular/extra-curricular, fulltime/parttime, bachelor/masters, programme/college. This is another complicating factor that needs to be taken into account to set quality assurance criteria and procedures. To proceed, we need more common ground about what defines an honours programme. The "Basic Characteristics of a Fully Developed Honours Program" of the National Collegiate Honours Council (NCHC) of the USA can be a source of inspiration since it is a worthwhile series of characteristics which have been updated to new insights over time. An example in the Netherlands is the 'ten key points for an honours programme' (Van Eijl, Pilot \& Wolfensberger, 2010, p. 47):

1. Mission-statement as point of entry for an honours programme.

2. Selection of students, also with respect to potential talent.

3. Teachers as source of inspiration for the students.

4. Honours pedagogy: challenge, authenticity, complex issues and discovery learning.

5. Programme with depth and broadness and diversity of skills and contact with employers.

6. Excellence is valued, space for new ideas and initiatives are facilitated.

7. Throughout the programme teacher feedback, peer feedback and coaching for individual talent development and personal development are important.

8. Students stimulate each other by teamwork, honours communities and extracurricular activities.

9. The programme is sufficient in size and duration, so talent can develop.

10. The programme has a dedicated organization with sufficient institutional influence and means and with co-operation of students. 
To arrive at this common ground about honours programmes we need a joint effort of honours teachers, students and their institutes to discuss this and come to (inter)national cooperation. This common ground will facilitate the exchange of experiences around honours and lead to an agenda for publications, activities and the development of peer reviews. Good contacts between Dutch honours teachers and NCHC exist already for more than ten years. New networks of contacts around honours are now being established both nationally in the Netherlands and on a European level (European Honours Council). Also, honours students in the Netherlands are forming their own networks.

\subsection{Quality assurance tools in American, Dutch and Belgian honours programmes} Since the USA already has a long lasting tradition in honours, they use a spectrum of possibilities (Van Eijl, Pilot \& Heemskerk, 2013) to assure quality control in honours programmes. These are for the USA:

- A system of course approval within an institution

- Internal evaluation of honours courses and programmes

- Annual reports of an honours programme

- Possibility of a site visit by NCHC trained site visitors. The "basic characteristics of a fully developed honours programme" are starting point for these site visits.

- Experiments with certification (Smith, 2015)

- National and local conferences

- Handbooks, other publications, discussions on the internet and a website to share knowledge and experience.

We can find similar quality assurance tools being used in the Netherlands and increasingly in Belgium as well:

- Internal approval of courses

- Internal evaluation of courses and programmes for feedback, learning about the programme and improvement (e.g. University of Antwerp in this paper)

- Honours conferences \& publications (books and articles) as a help to arrive at a common ground for an approach for quality assurance

- Experiments with internal audits (e.g. at Hanze UAS in this paper)

- Experiments with internal certification (e.g. at Utrecht University all honours programmes have just been internally certified based on a set of characteristics the university wants to be present in all their honours programmes)

- Experiments with external certification (e.g. Hanze UAS \& Hobéon in this paper)

- External audit with the "Sirius Compass" regarding design and implementation of honours programmes. Auditors were 'critical friends' who gave also lots of constructive feedback (Sirius Programma, 2016).

In the Sirius Compass (see figure 1), important elements for the audit are grouped: Teachers, Culture and Community building, Added value and Relationship with employers, Educational chain (honours programmes aren't isolated but part of a larger educational chain) and Networking and Organization and Governance.

The audit committee of the Sirius project has a lot of experience in auditing honours programmes in nearly twenty Dutch universities, both research universities and universities of applied sciences. In their last report, named “Don't regulate, but challenge: many roads 
lead to excellence" (Auditcommissie Sirius, 2014), they emphasize the importance of diversity in honours education. The use of the Sirius Compass turned out to fit this diversity.

Figure 1: The Sirius Compass for auditing honours programmes in The Netherlands

\section{"Sirius Compass"}

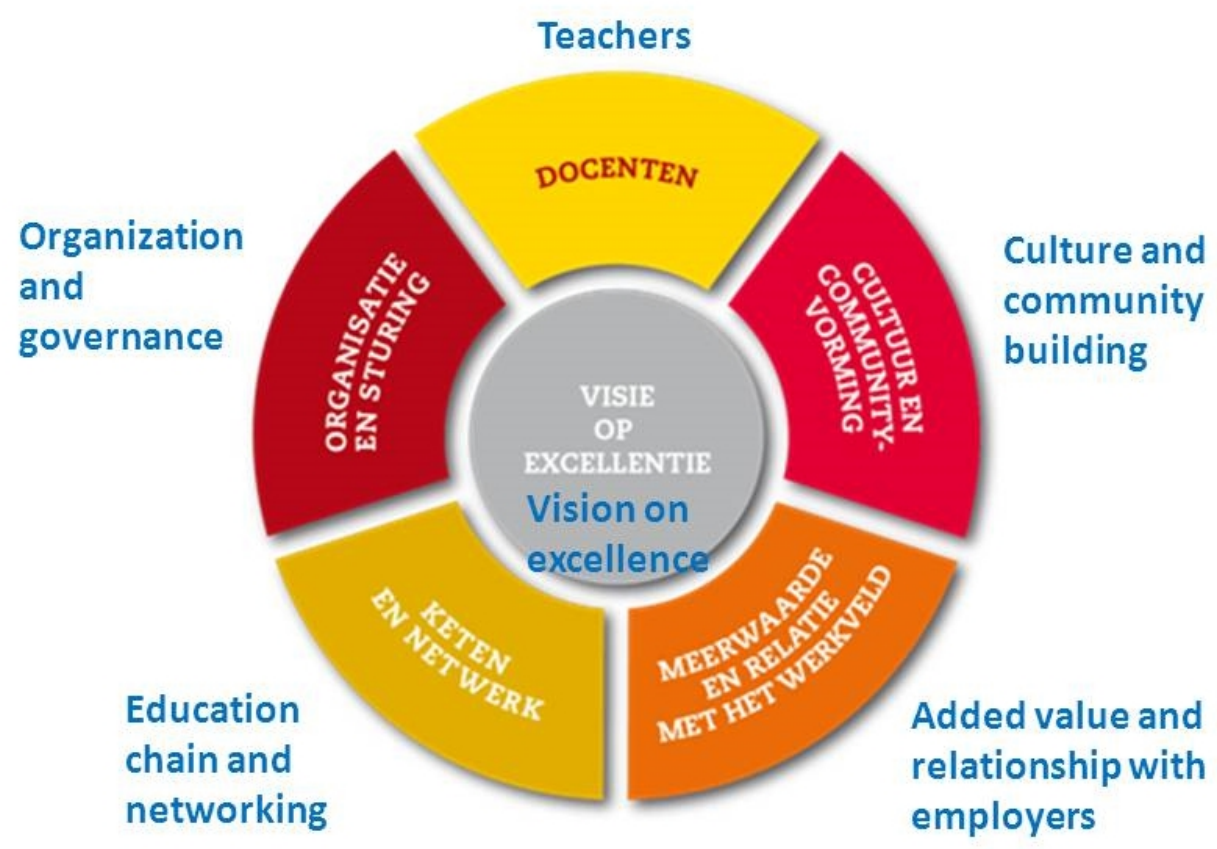

\subsection{The dilemma between quality assurance and freedom and creativity in honours}

Usually quality assurance, certification and accreditation come with extensive standardised checklists and a set of rules that may form a serious limitation for an honours programme, because one of the key honours features is facilitation of great ideas of students. Flexibility for students is important but a form of quality control is also important as feedback for the organizers of the programme and for stakeholders.

Therefore freedom and flexibility are a necessary component in an honours programme. This dilemma has been described by John Zubizarreta (2013) of the NCHC as follows: 'With certification we have to navigate between what we value in honours (risk taking, creativity) and standardization (bureaucracy). In the spirit of honours, making mistakes is part of a personal development process and just part of the game. This 'option to fail' should be maintained in order to keep the spirit of honours creative and happy.'

\subsection{Some other points of attention concerning quality assurance:}

- Be sure to involve honours students in evaluations, programme reviews and certification: they are in a certain way the experts and they make the feedback richer. Students want to address opportunities to improve their programmes and are therefore a driving force in the field of quality assurance.

- Input of external partners in quality assurance/control is useful, however, you should think about how you can properly work together, use their feedback and keep an open communication. 
- Whatever you do, make it visible! An annual report on results, progress, and quality assurance activities, shows an external audience what is happening in honours and makes it more transparent.

\subsection{Points brought up during discussion}

- In some honours programmes, students have lots of freedom and can make contracts with individual teachers on an individual basis, which makes it very difficult to assure the quality of these contracts. One of the participants explained that they work with an Honours council which consists of members of departments/schools with a relation to an honours programme or honours college and administrative members. This Honours council reviews all honours thesis proposals and all programme and course content. They have worked out basic checklists to help guide students and teachers to make a proposal and to help the Honours council to assess the quality at the same time. The Honours council works year-round in a continuous process for improvement.

- At Windesheim University of Applied Sciences in Zwolle (Netherlands), the quality is evaluated after every course. The students discuss the possibilities to improve the course with the teacher. The influence of students is high, things change according to their suggestions. Talking informally with students can sometimes be confronting for teachers but can also help to discover why something is great or isn't working. In the same University of Applied Sciences, students evaluate the entire programme, have a counselling meeting three times a year and can join panel discussions.

- Student satisfaction is one part of quality assurance, but isn't the only important factor to take into account. At Utrecht University, they heavily invest in the quality of the teachers engaged in honours programmes. There is a very strict selection based on a list of criteria. $50 \%$ of teacher applications are declined. It is very nice to have such an interest of teachers to become an honours teacher.

- A pitfall of having quality assurance tools in place is the amount of time a teacher needs to work on quality assurance in the honours programme (according to a participant of the session). Understaffing wasn't the reason for this problem but the administrative workload for quality assurance means less time for teachers to spend on their honours teaching.

- What is honours quality? How can you see if honours learning competences are achieved and how do you define the honours level? For some disciplinary programmes, regular learning goals are 'topped' or 'extended'. However, for the majority of programmes, we claim that they are 'different', not 'more of the same'. In interdisciplinary programmes, other learning goals are defined, for instance focusing on personal and skills development. In an honours bachelor thesis, an extra learning goal (often across different modules or disciplines) should be defined by the supervisor and the honours student.

- No fixed goals. It is important to let the honours student know that some honours courses are regularly changing because students' needs are changing over the years. Students can help in improving the programme. If, on the other hand, you let your honours students choose between all courses in the institution, be aware that they might not have the quality you are looking for or the honours student could have different expectations about the course. The learning gain is in that case more about 
the personal development the course brought to the student or the complexity of new things learned or other things students gained in the course.

- It is always a good thing when members of departments/schools interact with each other and learn and engage in quality assurance together. Not only students but also teachers form an honours community.

\section{Case study of Hanze University of Applied Science - Hobéon Quality Certification (an example of external quality assurance)}

At the Hanze University of Applied Sciences (Hanze UAS), all 17 schools have honours programmes. They use an internal certification process which is certified externally. This setup was chosen to externally validate the process of internal certification. The external validation is done by an organization specialized in quality assurance: Hobéon.

At Hanze UAS there are different types of honours programmes: most programmes have a semester of 30 ECTS in addition to the regular bachelor programme as an extra-curricular honours talent programme. A third of each honours talent programme of a student is interdisciplinary. Hanze UAS offers a mix of several interdisciplinary themes and projects. Other honours programmes at Hanze UAS are intra-curricular. In these programmes, for instance, students can do an honours internship or graduate with an honours thesis project. Besides the above mentioned forms of honours programmes, Hanze UAS has a number of honours minors which are open to all students who meet the requirements.

The quality assurance procedures are quite elaborate at Hanze UAS. Every honours programme applies for admission to the Hanze Honours College before it can be implemented. By using an extensive assessment framework, the Hanze Honours College audits its honours programmes once students have graduated from the programme (for a minor this will be after half a year, for a talent programme after three years). A successful audit leads to an internal certification of that honours programme. In preparation for the audit, a self-evaluation is written for the honours programme. At the audit day an audit team speaks with teachers, students, alumni and management. The audit team consists of a representative of the Hanze Honours College, an honours teacher from a different honours programme, an experienced auditor, an honours student and a writer for the audit report.

\subsection{Assessment framework}

The assessment framework uses six aspects of assessment:

1. Is there a mission defined and what is the proposed end level of the programme? It should address a complex problem, it should thrive on own initiatives of students, it should be deepening (specialized) but mostly widening (interdisciplinary).

2. In what way does the programme use honours pedagogy and methodology and how are teachers selected?

3. Are students selected in a fair way?

4. Are there activities to establish or maintain the honours community?

5. How is quality assurance organized within the programme?

6. In what way is the end level assessed? Students' end products are reviewed.

This whole process is developed together with Hobéon, which is a well-known quality agency in the Netherlands. Hobéon has awarded Hanze Honours College a Quality Label for their certification process; it is focussing mostly at the process of certification, thereby assuming 
quality of individual honours programmes is assured by the above mentioned audits. It is an external validation of the internal certification process of honours programmes at Hanze UAS. Hobéon sits in on an internal audit every three years. The internal audits follow the same time frame of six years as the regular accreditation cycle with a lighter midterm review.

Hanze UAS applied at NVAO (Dutch Flemish accreditation organization) for a special recognition (a so called "Bijzonder kenmerk") for the entirety of the quality assurance process and was awarded this recognition in March 2016.

\subsection{Points brought up during discussion}

- Is a quality assurance system needed to secure the quality of honours programmes? Could it be argued that the honours environment doesn't need a formal quality check?

- Make sure that the internal audits aren't full blown accreditations: they require a lot of administrative paperwork and paperwork does not always reflect reality. It would be great to have the programme show itself in a free format form balanced with some limited common assessment framework as a way of having 'bounded freedom'. The very detailed framework sometimes falls back on being just a checklist. The amount of paperwork should be kept limited. A site visit is always very valuable because there is conversation about the value of the programme and an exchange of ideas.

- The atmosphere in the institute stimulates teachers to act in a certain way. If you want your students to take responsibility and have the possibility to be creative, you need an open atmosphere. The teachers also need this atmosphere to bring openness to the students (including the freedom to fail).

- Sometimes having an external certification can give a sort of 'protection' during budget cuts. A good communication with your own management/executive board is very important.

- The goal is to improve your programme so if the incentive of having a good quality assurance system comes from inside the institute as a result of wanting to do your job the best way you can, it gives a different perspective than just having quality assurance systems in place because it is an obligation.

- There are institutions thinking about developing certain internal certification processes themselves. Credibility increases if quality assurance is taken seriously. Developing a common ground is a first step.

\section{Example of internal certification of honours programmes at Utrecht University, The Netherlands}

Utrecht University, a research university, has a long standing tradition in honours. The first honours programmes started in 1993 in Geosciences and Veterinary Sciences. This was followed by the University College Utrecht (1998) and other departments/schools of the university. After an experimental period of diversity in honours the university agreed upon some basic requirements for departments/schools to provide an honours certificate to honours students who completed their honours programmes successfully (Van der Vaart \& Zunderdorp, 2016). Point of entry is that honours programmes are diverse because of 
different cultures in departments/schools, differences between bachelor and master and the principle of demand-drivenness by students.

\subsection{Criteria for internal certification}

A university committee for certification decided upon a set of criteria for bachelor honours programmes, which are summarized as follows:

- Students can start in the beginning of their first (freshmen) year, or during their first year or at the beginning of their second (sophomore) year. This is different in each department/school.

- Students participate at least two years in the honours programme and its honours community.

- Students can only participate and stay in the honours programme if their study results belong to the top $20 \%$ of their year.

- Students can graduate based on their study results as described in the credit point registration system of the university or/and their honours portfolio. In both cases active participation in the honours community is compulsory. An honours coordinator can in individual cases deviate from these rules.

Students who meet the requirements will receive an honours certificate. Also, all honours courses are included in their transcript of records and are clearly marked as such.

- Besides these requirements, the committee for certification has additional requirements for the content of the honours programmes such as (Zunderdorp, 2016):

- Student demand-drivenness is a key requirement.

- A combination of discipline oriented and interdisciplinary activities is required.

- 45 ECTS (European Credits) on honours level of which 15 ECTS at most is extracurricular and the rest of the credits is imbedded in the degree programme (total credits required for the bachelor is 180 ECTS).

- International study activities can be realized in different ways (participation in an exchange programme, undergraduate research in a foreign country, excursions with the honours community, etc.).

\subsection{Internal audit}

The committee organized an internal audit of the honours programmes in the departments/schools (Zunderdorp, 2016). Based on the outcomes of this audit the committee gave advice to the board of the university. This board decided on the certification of the honours programmes (and receive extra money and the right to hand over a certificate to the students who had completed the honours programme satisfactory). The committee acted as a 'critical friend' and gave all honours programmes recommendations. Later, the honours dean visited the departments/schools to monitor the state of the honours programmes and checked if support was necessary for the implementation of the recommendations.

The regulations for the honours programmes became part of the standard regulations for exams (model OER). Regular meetings between the honours dean and the directors of the honours programmes are organized to align the honours programmes between departments/schools. The deans of the departments/schools have the final responsibility for the quality of the honours programmes. The quality assurance of the interdisciplinary honours activities is under development. 


\subsection{Benchmark audits}

The national network of honours deans of Dutch research universities is looking into the possibility of organizing benchmark audits in which they visit each other, as has been done by the audit committee of the Sirius programme (2014) with a minimum of bureaucracy. Departments of Utrecht University have to involve honours programmes in the cycle of quality assurance of their programmes (with honours committees of teachers and students, evaluation panels, standard course evaluations etc.). In the coming two years, meetings between honours teachers within the university will be organized to exchange their experiences in the honours programmes.

\section{Case study of incorporation of regular quality assurance tools in an honours programme at the University of Antwerp (an example of internal quality assurance)}

At the University of Antwerp in the Faculty of Pharmaceutical, Biomedical and Veterinary Sciences, the honours college was first organized in 2011 and focusses mainly on a quick engagement in scientific research. The students are selected at the start of their second bachelor year based on grades, motivation letter, a selection interview and on how they can critically look at a scientific paper. One of the limitations of the programme is the fact that only 12 students are allowed to enter the programme each year. Once selected, students start exploring the research lab by following a tour, sitting in on lab meetings and other activities. They write about their experiences, are more familiar with a lab environment and gain ideas for their own research internship. Next, they propose a lab for their research internship and start drawing up a plan for it as well. The internship itself is about three weeks lab work guided by a talent coach appointed in the research lab. The internship is mostly performed during summer break to avoid interference with their regular programmes as it is an extra-curricular programme of around 18 ECTS. As for reporting, the students present their preliminary results to each other and the new candidates and they write a research article about their subject. During this year, they work on their communication and writing skills as well as their research skills.

Finally, since we aim for our students to be interested in more than science alone, they follow a lecture cycle with debate and write a paper about a non-scientific subject. As a teambuilding moment, the students organize an honours day trip for both years of honours college students during the Easter break. When they are successful, they receive an honours certificate signed by the dean and their talent coach.

\subsection{Now, what went wrong and how did we fix it?}

Our first Honours College group of students diminished after the first semester from 10 to 3 students. This massive dropout wasn't really what the organizers expected, so a focus group discussion with the students was organized. Since the programme at that time started with the interdisciplinary part of the programme, the students felt really out of their comfort zone, they didn't know where to start and had put ten times more effort in the assignment then was expected; they were just lost. On top of this, they didn't have alumni to fall back on, there wasn't a clear contact person or real guidelines and overall, the communication was lacking in efficiency. Students were left with too much freedom and it became uncomfortable for them. 
As a result of this first focus group discussion and the ones in the following years, a lot has changed:

- A website with information, clear goals and contact details was developed.

- The current programme starts with the disciplinary part and gives different interdisciplinary possibilities.

- Students were invited to an extended information session where they are informed about the goals and outcomes of the programme. A large part of this information session consists of presentations of honours college projects by the students who are in their second year of the programme. This immediately gives the new candidates a great view on the possibilities of the programme and what they can achieve in one year.

- Students have a designated talent coach during their internship and a coordinator of the programme was assigned. The coordinator is the first contact point for the students when they have questions. The coordinator supplies the students with guidelines and feedback. Evaluation criteria are defined for their internship in the research group. The talent coaches use rubrics to score the honours students.

- Students are asked to organize an Honours college day, a trip to an interesting company with all honours college students.

- The study success of the students is checked and the students are regularly informed about their progress in the programme.

- Students are able to give individual feedback besides the informal contact moments after a year and participate in a focus group discussion at the end of the programme where changes, difficulties and opportunities are discussed. They also get the possibility to give feedback about the coordinator to a neutral party.

These changes make it more clear for the students what the expectations of the programme entail and who they can address if they have questions: it is easier for them to find the right information. As a consequence, the dropout decreased immediately following these changes which indicated the importance of a good communication and good information flow. In the coming years, the programme will keep on evolving whilst incorporating feedback from the participating students.

\section{Concluding remarks}

Some general conclusions can be drawn from the discussions:

1. Most honours programmes are very articulate about the fact that they are 'different', stimulate creativity and offer the freedom to fail and to learn from failure. However, one way or another, a form of quality assurance is needed to continuously improve. So honours educators must at least care for internal quality control.

2. Honours programmes are very diverse in structure, content and organization. For those involved in honours programmes, common ground is necessary to make explicit what the key characteristics of an honours programme are. This can also help outsiders to get a better picture of the value of these programmes. 
3. Student involvement is stimulating for the engagement of everybody in the quality control and development process of an honours programme.

4. It is a challenge to find an external certification method that doesn't discourage the honours spirit and is able to capture the essence of the programme with a limited amount of preparations for the staff involved. If, for instance, efficient annual reports are made and goals are defined, an external audience can inform themselves about the honours programme and its outcomes. An annual report describes the goals of the honours programme, the programme activities and whether the goals have been reached as well as some quantitative data like the number of students who started the programme and the number of students that successfully completed the programme. Other topics could be the way students were selected for the programme, special accomplishments and the profile of the teachers involved.

5. Being involved in honours initiatives is like a warm bath, a great learning climate for students and teachers. Honours students do remarkable things and capture the interest from outside and inside the institution. This exposure is important for the sustainability of an honours programme. For a teacher, it is the most wonderful experience to have students sitting in the front row, to have them continuously ask questions and to be engaged. This is what higher education is meant for. It would be great if more teachers were able to take part in this highly enjoyable form of education. The authors really feel that the honours programmes may reflect the quality of tomorrow's higher education.

\section{References}

Auditcommissie Sirius (2014). Niet reguleren, maar uitdagen: de vele wegen die leiden naar excellentie. Overall auditrapport Sirius Programma 2008-2014. [Translation: "Do not control but challenge: the many roads to excellence. Overall audit report of the Sirius Programme 2008 - 2014"]. Den Haag, The Netherlands: Platform Bèta Techniek. https://www.siriusprogramma.nl/media/files/publicaties/Def \%20webversie\%200verall\%20 audit\%202014.pdf

Eijl, P.J. van, Pilot, A. \& Heemskerk, R. (2013). Kwaliteitszorg voor honoursprogramma's. [Translation: "Quality assurance for honours programmes"] In: R. Coppoolse, P.J. van Eijl \& A. Pilot, Hoogvliegers, ontwikkeling naar professionele excellentie. [High flyers, development towards professional excellence] (pp. 195-208 ). Rotterdam: Rotterdam University Press. In Dutch (full text): http://hr.surfsharekit.nl:8080/get/smpid:60567/DS3/ English synopsis: https://www.researchgate.net/profile/Pj_Eijl/contributions

Eijl, P.J. van, Pilot, A, \& Wolfensberger, M.V.C. (2010). Talent voor morgen [Translation: Talent for tomorrow]. Groningen: Noordhoff Uitgevers.

NCHC (National Collegiate Honors Council) (2016). Basic Characteristics of a Fully Developed Honours Program. Available online: http://nchchonors.org/(accessed 4/7/2016) 
Sirius programma (2016). Het Sirius Kompas voor de audit van honoursprogramma's in Nederland. [Translation: "The Sirius Compass for auditing honours programmes in The Netherlands"]. Available online: https://www.siriusprogramma.nl/publicaties/het-siriuskompas\#.V3pXJ03VzIU (accessed 4/7/2016)

Smith, P.J. (2015). A Quality Instrument for Effective Honors Program Review. Honors in Practice - Online Archive. Paper 242. Available online:

http://digitalcommons.unl.edu/nchchip/242 (accessed 4/7/2016)

Vaart, R. van der \& Zunderdorp, K. (2016). Werkprogramma honoursonderwijs 2016-2018. [Translation: "Policy for honours education, 2016-2018"]. Utrecht, The Netherlands: Universiteit Utrecht, Nota Universiteitsraad, UR nummer 16.070.

Zubizarreta, J. (2013). Private communication, June 2013.

Zunderdorp, K. (2016). Private communication, October 2016 